\section{MARIÁTEGUI, ASSINANTE DE CLARTÉ}

Mariátegui, Clarté's subscriber
Carmen Susana

TORNQUIST

(D) carmentornquist@hotmail.com

Universidade do Estado de Santa Catarina

Florianópolis, SC, Brasil

\section{RESUMO}

Este artigo analisa a interlocução de José Carlos Mariátegui com o movimento Clarté, grupo de intelectuais franceses que editou entre 1919 e 1928 um periódico de mesmo nome, cuja distribuição extrapolou os marcos dos países francófonos. Além de referências diretas ao grupo e compartilhamento de temas e autores comuns, Mariátegui traduziu e divulgou matérias editadas por Clarté, expressando uma prática comum à época: o intercâmbio permanente e a interlocução feita entre periódicos, consolidando uma esfera pública de intenso e dinâmico debate. Esse processo estabeleceu uma rede editorial de caráter internacional, articulando a América do Sul ao mundo, de fundamental importância na organização da cultura, tarefa que Mariátegui assumiu como prioritária ao retornar de sua viagem à Europa.

Palavras-chave: Mariátegui, Clarté, editorialismo programático, marxismo.

\begin{abstract}
This article analyzes the dialogue between José Carlos Mariátegui and Clarté movement, a group of French intellectuals who, between 1919 and 1928, the distribution of which crossed the boundaries of the Frenchspeaking countries. In addition to direct references to the group and the sharing of themes and common authors, Mariátegui translated and published articles edited by Clarté, expressing a common practice at the time: the permanent exchange and interlocution between and by the journals, consolidating a public sphere of intense and dynamic debate. This process consolidated an editorial network of international character, articulating South America with the world, what was fundamental in the organization of culture, a task Mariátegui assumed as a priority when returning from his trip to Europe.
\end{abstract}

Keywords: Mariátegui, Clarté, programmatic editorialism, marxism. 
Sabemos que a trajetória de grandes pensadores não é apenas fruto da sua genialidade e talento, mas também da sua capacidade de absorver e elaborar processos candentes e inovadores que estiveram presentes nos contextos históricos em que viveram. José Carlos Mariátegui foi um destes pensadores. As razões pelas quais conseguiu fazer uma análise acurada de uma situação histórica concreta, exemplarmente sistematizada em Sete ensaios de interpretação da realidade peruana, são alvo de um debate permanente, em especial entre aqueles que seguem empenhados em compreender as razões da subalternidade de nossa região no sistema capitalista mundial. Sua atualidade, reivindicada por estudiosos de diferentes perspectivas teóricas, reside na chave anti-positivista de sua interpretação, que estaria relacionada, de um lado, à sua formação ideológica (europeia) e, de outro, a seu permanente vínculo com os sujeitos políticos que emergiram no contexto em que viveu'.

Mariátegui faz muitas referências a Clarté, um dos primeiros movimentos comunistas da França. Fala diretamente do grupo no artigo "El grupo suprarealista y Clarté", publicado em Variedades em julho de 1926, e em "El Grupo Clarté”, editado na coletânea de 1925 La escena contemporánea. Ou, ainda, do artigo "La lucha final”, publicado na revista Mundial em março de 1925, dedicado a analisar a Revolução Soviética e no qual ele se refere a uma das editoras da revista Clarté - Madeleine Marx - como "uma das mulheres de letras mais inquietas e mais modernas da França contemporânea (MARIÁTEGUI, 1994a, p. 499).

Mariátegui conheceu Clarté em seus primeiros dias, quando chega a Europa, e estabelece, a partir de então, um vínculo que se estende até o final de sua vida. Parto da premissa de que ter sido leitor assíduo e assinante da revista Clarté deixou marcas importantes na obra de Mariátegui. Sobre este aspecto, considero bastante pertinentes as afirmações de Robert Paris:

Se é certo que em sua essência a formação ideológica de Mariátegui é, em primeira chave, italiana, as formas - acreditamos - foram tomadas de Clarté. Este é, na verdade, um elemento comum àquele período: de Claridad, de Haya de la Torre, a Aníbal Ponce ou ao Ordine Nuovo de Gramsci, as práticas dos intelectuais dos anos 1920 e 1930 seguem ancoradas sob o signo da experiência prodigiosa inaugurada por Henri Barbusse (PARIS, 1969, p. 9, tradução livre).

Nesse sentido, destacarei, em particular, seu trabalho como periodista, expresso de forma mais clara na direção da Librería Minerva e da Sociedad Editora Amauta ${ }^{2}$, e na organização da revista Amauta e do jornal Labor. No entanto, apesar de neste artigo tratar da influência de Clarté sobre Mariátegui - entendendo influência como uma escolha e não uma absorção inconsciente -, não pretendo afirmar que ela se sobrepôs a outras experiências como, notadamente, é o caso do impacto que o periódico L'Ordine Nuovo, liderado por Gramsci, exerceu sobre o autor (BEIGEL, 2006). Assim como em Gramsci, a leitura do marxismo feita por Mariátegui contém vários elementos do mesmo contexto histórico da Itália, do início do século XX, especialmente 
a experiência operária do "Biênio Vermelho", do ponto de vista político, e filosoficamente pela hegemonia do historicismo, sob influência de Benedetto Croce (BEIGEL, 2005).

Este artigo se apoia em pesquisa feita nos exemplares microfilmados do Bulletin e da revista Clarté, publicados em Paris entre 1919 e 1928², e nos exemplares em facsímile da revista Amauta, editada no Peru entre 1926 e 19304, bem como em artigos compilados na obra Mariátegui Total. Também foram analisadas as cartas trocadas entre Mariátegui e outros escritores e editores, que expressam a centralidade das correspondências na interlocução permanente do peruano com seus pares e a dinamicidade típica das redes editorialistas de seu tempo.

Os materiais foram examinados à luz da análise de conteúdo, considerando a necessidade de tratar de forma específica cada tipo de texto (cartas, artigos, editoriais, livros). Sublinhamos a especificidade das revistas, fonte prioritária desta investigação. Diferentemente dos jornais, submetidos ao imediatismo cotidiano, e dos livros, marcados pela transcendência, as revistas ocupariam um lugar intermediário entre essas duas "temporalidades" (CRESPO, 2011, p. 99). No que tange às correspondências trocadas entre Mariátegui e seus interlocutores, trabalhei com a ideia de relativizar a distinção entre público e privado, já que se trata de personalidades públicas, bem como a natureza dos temas abordados (NETTER, 1990, p. 5-9).

Busco mostrar que o contato de Mariátegui com Clarté contribuiu para o seu trabalho como organizador da cultura após o seu retorno da Europa, em 1923. Esse período, considerado pelos seus biógrafos como o mais importante na sua produção intelectual - e ao qual ele se refere como correspondendo a sua "tarefa americana" - foi marcado pela dedicação à estruturação de um projeto socialista para o Peru, no qual a socialização da cultura e a construção de uma consciência sobre as condições concretas da região serão fundamentais.

\section{Clarté: uma trajetória dinâmica}

O Grupo Clarté foi um movimento composto inicialmente por intelectuais franceses que criou um Bulletin e, a seguir, uma revista com o mesmo nome, como forma de divulgar suas ideias. Fazia parte das atribuições dos clartéistes - como eram chamados os ativistas diretamente ligados ao projeto - participar de reuniões e debates em bairros de Paris ou de outras cidades onde se instituíam grupos de adeptos de seus ideais, travando ao vivo os debates veiculados pela revista. Mais do que um grupo editorial, Clarté foi um movimento. Também é considerado o primeiro periódico de orientação comunista da França e o principal divulgador da revolução soviética na Europa, entre um amplo conjunto de publicações que compõem o campo editorial socialista naquele país (RACINE, 1967). Uma detalhada análise dessa trajetória do grupo foi feita, recentemente, por Alain Cuenot (2003a; 2003b). O historiador classifica, em linhas gerais, duas fases de Clarté: a primeira, entre 1919 e 1925, corresponde à passagem de uma ideologia pacifista ao que ele chama de internacionalismo proletário, e a segunda, entre 1926 e 1928, marcada pela relação com o surrealismo e a posterior identificação com o trotskismo. Mas, neste artigo, o percurso do grupo será tratado de forma mais abrangente, tendo em conta algumas características 
centrais que atravessam esses períodos. Clarté foi marcada pela dinamicidade e pela polêmica constante e por isto paradigmática do editorialismo de vanguarda dos anos de 1920, expressando os principais processos políticos, intelectuais e artísticos vivenciados na Europa. A primeira edição do periódico Clarté se dá em dezembro de 1919 e se expressa em um Bulletin, publicado quinzenalmente. Rapidamente, o grupo que compõe o comitê editorial logra transformá-lo em hebdomadaire, e a publicação torna-se semanal, até o final de seus dias, em 1928, com apenas algumas lacunas em termos de periodicidade ${ }^{5}$.

Em vários de seus números aparece, após o nome Clarté, um subtítulo: Bulletin Français de I'Internationale de la Pensée (Boletim Francês da Internacional do Pensamento) e consignas como "Façamos uma Revolução nos Espíritos" e "Pela construção de uma Internacional dos Espíritos". Se Barbusse foi o seu mais conhecido membro, não há dúvida de que a iniciativa somente pôde se transformar em realidade porque contou com o apoio de vários outros ativistas igualmente influentes no campo socialista, dentre os quais destacam-se Paul Vaillant-Couturier, Raymond Lefebvre ${ }^{6}$, Madeleine Marx e Michel Fourrier. Barbusse foi o principal interlocutor francês de Mariátegui até o final de sua vida, e a sua célebre frase a respeito do peruano ficou imortalizada em seu túmulo, em Lima7. Mariátegui havia lido um romance de Barbusse ainda no Peru e, ao chegar em Paris, depara-se com outro livro seu (Le feu), romance de guerra que ganhou o Prêmio Goncourt em 1916. A partir de sua admiração pelo escritor, Mariátegui procura Barbusse em dezembro de 1919, em sua rápida passagem por Paris, antes de mudar-se para a Itália. A partir desse encontro, no qual conheceu as "Oficinas de Clarté", poucos dias antes da edição do seu primeiro Bulletin, a relação com Barbusse e com o grupo-movimento será permanente.

Henri Barbusse, além de ser escritor, tinha uma participação política situada no âmbito do movimento pacifista desencadeado pela guerra de 1914-1918. Estava, nesse momento, articulando-se com outros intelectuais e escritores da Europa, muitos dos quais socialistas, em torno da Associação Republicana dos Antigos Combatentes (A.R.A.C.). À luz de suas experiências pessoais nas frentes de batalha, organizaram-se no combate político à guerra. A I Guerra foi por eles considerada a maior expressão do retrocesso da humanidade, um atentado ao espírito das "Luzes" e às possibilidades de emancipação humana. Juntamente com outros intelectuais europeus, como Romain Rolland, que havia se posicionado contra a Guerra, Barbusse propõe a criação de um movimento intelectual de caráter internacional e pacifista. O nome do periódico expressa a perspectiva (em português, Clarté corresponde a Claridade), e o primeiro logotipo do Bulletin, depois utilizado em tamanho diminuto na revista entre 1921 e 1922, fazia referência explícita às "luzes que iluminam a consciência. Na figura 01, pode-se ver, ao centro, a imagem de uma mulher iluminada por raios de luz, bem como a referência ao diretor - Henri Barbusse, logo abaixo do titulo, e um sumario com os artigos de fundo, com referência a seus autores.

O diálogo permanente entre equipe editorial e seus leitores e leitoras era expresso de diferentes formas, na revista. Nesta via, eram feitas solicitação de apoio econômico, via assinaturas, já que o periódico visava ser independente e autônomo. Os assinantes 


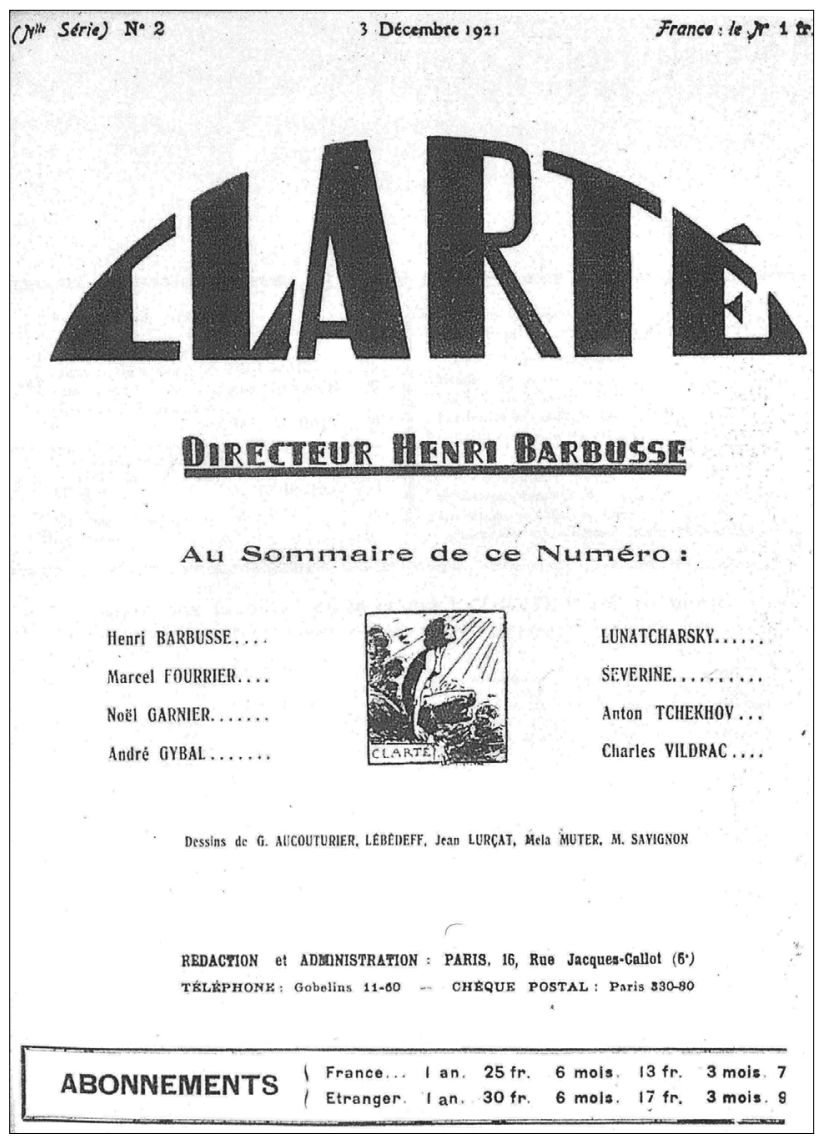

Fig. 01. Capa da Revista Clarté, n. 3, Dezembro de 1921.

eram considerados "amigos de Clarté", o que significava que, além de contribuírem com recursos econômicos para a manutenção da revista, alinhavam-se à orientação ideológica do grupo. Esta proposta, todavia, não pôde sempre ser cumprido à risca, e Clarté passou a contar, sobretudo a partir de 1923, com a presença de publicidade, em sua maioria de editoras e livrarias e produtos relacionados ao mundo das letras, como estantes, mesas de estudo, bem como anúncios de serviços profissionais ligados ao ensino de línguas. A temática da autonomia econômica e da independência política dela decorrente foi um dos pontos de grande importância para vários periódicos similares, e aparece também na pauta de Mariátegui e de outros projetos latino-americanos. 
Desde os primeiros números os leitores e leitoras podiam apreciar desenhos relativos à personalidades como Rosa Luxemburgo, Karl Liebknecht, Lênin, Marx. Destaca-se também a reprodução de xilogravuras e desenhos de artistas ligados ao surrealismo, ao futurismo, dadaísmo e ao expressionismo alemão. Obras de Georges Grosz, Mela Muter, Franz Masereel, Henri Matisse, Pablo Picasso e outros eram frequentes na revista, as vezes colocadas na própria capa, como a que segue, com um trabalho de artista russo Serge Fotinsky. Esta obra, aliás, circulou em vários outros periódicos da época, inclusive na América latina.

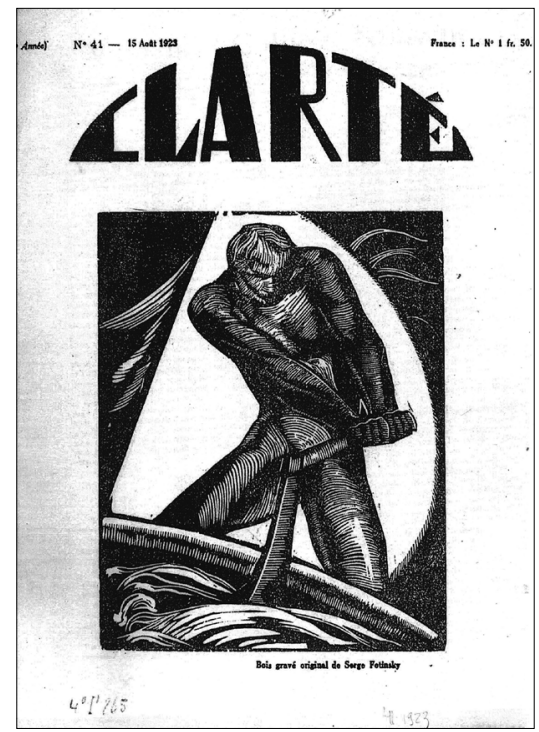

Fig. 02. Capa da Revista Clarté, n. 41, Agosto de 1923.

Fotografias também foram usadas, tanto avulsas quanto junto a analises da situação política de países que vivam processos 'revolucionários'. A presença destas era acompanhada de artigos ou dizeres que contestavam claramente as matérias divulgadas pela imprensa burguesa e afirmavam o compromisso de Clarté com a verdade. Por exemplo, um mapa da "verdadeira" Russia foi publicado de forma reduzida, em 1920, e depois, vendido em tamanho maior, a preços módicos pela editora Clarté, objetivando difundir a representação correta, do ponto de vista cartográfico, do mapa mundial. O mesmo acontece com relação aos mapas da China e do Marrocos, alguns anos depois.

Artigos de caráter testemunhal, escritos por diferentes pessoas que viajavam para o país, foram frequentes em Clarté, como se pode ver, na figura 03.

A matéria Impressões da Rússia foi publicada em partes, por Magdeleine Marx, que fez parte da equipe editorial que criou o periódico, em 1919. O desenho que ilustra 


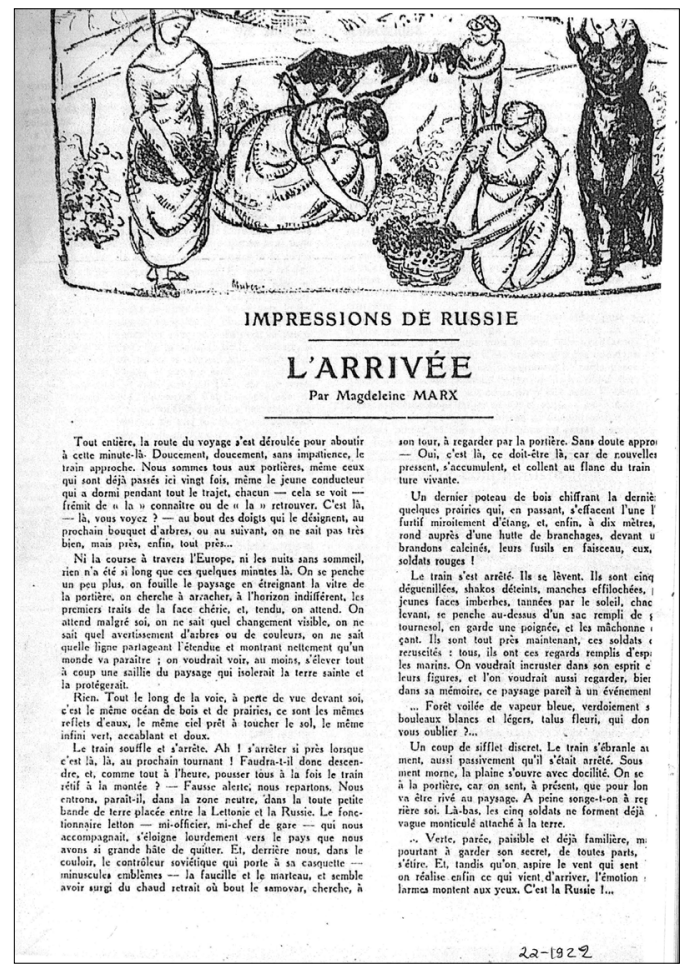

Fig. 03 - Revista Clarté, n. 22, Março de 1922.

esta parte do texto é de Mela Muter, que esteve presente por vários anos em Clarté. A presença de mulheres como autoras e do feminismo como um tema não é ocasional, em Clarté ${ }^{8}$ E, como vimos antes, Mariátegui refere-se à Madeleine Marx no artigo citado anteriormente, sobre a Revolução Russa. Em Clarté, ela se responsabilizou por inúmeras traduções de textos para o francês que originalmente estavam em alemão e em inglês, e escreveu livros como Fleme, em 1919 e Une Grande Grève aux États Unis, em 1927. Em 1923, publicou um livro sobre a Rússia chamado A luta final (C'est la Lutte Finale), em 1923. É provável que Mariátegui tenha tido contato com estes livros, inclusive para escrever seu artigo, que levou o nome do livro e que corresponde ao Hino da União Soviética e da Internacional.

A revista se estruturou com seções permanentes, como "La vie économique", "La vie politique", "La vie intelectuelle" "La vie sociale" "La vie de notre revue", entre outras, bem como listas dos assinantes, cartas de leitores, listas de livros e revistas recebidos - em geral, acompanhados de comentários críticos, e uma coluna contendo um rol de livros com preços acessíveis editados pela gráfica de Clarté. Campanhas 
em prol da leitura, como "o livro do mês", "o que ler nas férias", "livros para crianças", também fizeram parte das ações da revista, que não deixou de incluir uma ampla Campanha contra a Fome na Rússia com vistas a apoiar o povo russo contra o bloqueio econômico dos países europeus, ao longo de 1919. Destaca-se também a realização e publicação de "Enquetes", como exemplo a que foi feita por Clarté em 1927, cujos resultados são apreciados por Pierre Naville (1927) em artigo intitulado: "Nosso trabalho revolucionário - A enquete de Clarté" no qual analisa as respostas dos leitores, sobretudo europeus, ao questionário enviado pelos editores sobre os objetivos da revista. Nas revistas latino-americanas, a publicação de Encuestas também foi comum. Destacamos a discussão de Mariátegui sobre a conhecida enquete feita pelos surrealistas acerca do amor e da sexualidade, no artigo "El super-realismo y el amor”, artigo publicado na revista Mundial, em 1930 (MARIÁTEGUI, 1994, p. 568).

O periódico era distribuído pelo correio, cuja rapidez e eficiência não podem ser negligenciadas, sendo vendido em quiosques e também nos encontros de Clarté realizados em teatros e associações sindicais ou escolas. A publicação referia-se com frequência a datas comemorativas, seja de eventos (Revolução Soviética, Comuna de Paris, Dia do Trabalho, Grande Guerra etc.) ou de aniversários de líderes socialistas (Lênin, Marx, Raymond Lefebvre, Louise Michel, Rosa Luxemburgo)

Clarté, além das subseções na França e em outros países da Europa, teve núcleos e adeptos no Egito, em Cuba, no México, Argentina, Uruguai. A ligação entre esses núcleos, todavia, era bastante flexível, já que se tratava de um movimento cultural ou intelectual que não seguia modelos doutrinários rígidos. No Brasil, existiu um grupo Clarté entre 1921 e 1922, atuando no sudeste do país, que reuniu os membros do Grupo Comunista Brasileiro Zumbi (SILVA,2017). Foram importantes divulgadores da Revolução Soviética no país, mas sua trajetória foi curta e nos anos seguintes alguns de seus membros aderiram ao programa sindical de Getúlio Vargas, expressando uma leitura bastante peculiar das proposições clartéistes (HALL; PINHEIRO, 1986).

A presença de ilustrações de artistas das vanguardas e o permanente debate acerca da arte ancorava-se na percepção do grupo, da necessidade de promover rupturas em todos os níveis com a sociedade capitalista e com a moral burguesa. Era comum que as ilustrações fossem reproduzidas sem fazer referências a autoria ou fontes originais, expressando o comum acordo entre estes periódicos sobre a necessidade de socialização e popularização das produções e criações, sem referências a direitos autorais. Daí entendermos por que são replicados com frequência logotipos, textos, frases, nomes de seções, além de ilustrações.

A relação com o surrealismo foi bastante significativa na trajetória de Clarté, tendo havido uma proposta de criação de uma revista em comum com o grupo liderado por André Breton, em 1926. No número 79, último de 1925, Michel Fourrier faz uma análise da trajetória de Clarté em um editorial de quase dez páginas, intitulado: "De Clarté à la Guerre Civile”, anunciando sua transformação em La Guerre Civile para o ano seguinte. A revista conjunta não chegou a ser publicada, e Clarté voltou a circular com o mesmo nome. Esta tentativa, além da aproximação com os surrealistas, contudo, expressa também o acirramento dos conflitos ideológicos que envolviam 
Barbusse e um grupo que passou a criticar a condução da Revolução por Stalin, após a morte de Lenin.

Os conflitos decorriam dos diferentes posicionamentos de seus editores com o campo socialista, que nesse contexto vivenciava sucessivos embates decorrentes da criação da III Internacional, em 1919, e dos Partidos Comunistas a ela ligados, como o Partido Comunista Francês, criado em 1920. Esses embates demarcaram historicamente a cisão do campo socialista, tendo por eixo diferentes posicionamentos referentes à I Guerra e à II Internacional, e, depois, com relação a processos considerados revolucionários, como os ocorridos na Alemanha, na China, no Marrocos e outros países. Diferentes posicionamentos em relação aos desdobramentos do processo revolucionário soviético, sobretudo depois da morte de Lenin marcaram a trajetória cheia de tensões internas de Clarté, opondo a visão racionalista e pacifista de Barbusse à perspectiva bolchevique dos clartéistes mais jovens (CUENOT, 2003b).

Conflitos de outras ordens também se sucediam nas Oficinas de Clarté, referentes a diferentes proposições de caráter organizativo, editorial e também, conflitos pessoais, a estes articulados. Assim, muitas das polêmicas acerca desta questão foram explicitadas aos seus leitores. Por exemplo, no número 75, de 1925, um longo artigo escrito por Georges Michael, intitulado "Crise et réorganisation de Clarté", apresenta as bases e o método que levaria a nova equipe diretora a observar regras editoriais mais criteriosas. Esse artigo é acompanhado de uma carta de "demissão" de Jean Bernier, que contribuía regularmente com a revista, e uma introdução de Fourrier, na qual ele sublinha a importância de os leitores terem acesso ao debate interno e às diferentes versões de seus articulistas. Os constantes embates acerca da orientação política dos periódicos - por vezes visto como conflito entre ecletismo e doutrinarismo - foi um dos eixos da tensão entre Barbusse e os mais jovens clartéistes.

Segundo Clarté, os partidos e grupos filiados à II Internacional haviam se afastado da perspectiva revolucionária e internacionalista que estivera presente em sua criação. Nesse contexto, deve ser destacada a referência a Georges Sorel, intelectual francês que criticou duramente o sindicalismo reformista de seu tempo, a ele contrapondo a retomada do sindicalismo revolucionário. Autor de Reflexões sobre a violência, inspirador teórico do movimento dos Conselhos de Fábrica e do Biênio Vermelho, Sorel contou com a admiração de Lênin e foi referência constante para Gramsci (LIGUORI, 2017, p. 742). Foi uma referência frequente em Clarté, sobretudo quando a revista adquire um volume maior de páginas, entre os anos 1922 e 1925. Jean Bernier, Georges Michael e Marcel Fourrier, em especial, escrevem artigos de fôlego em que Sorel é referido constantemente, junto a Lênin, Marx, Rosa Luxemburgo. Como exemplo, citamos o número 21, de 1922, por ocasião de sua morte, Berth escreve um elogioso artigo sobre Sorel, colocando-o ao lado de Proudhon e de Marx, dizendo: "Sua ambição constante foi dotar o movimento operário de uma ideologia própria, capaz de alçá-lo à plena compreensão de sua missão histórica” (BERTH, 1922, p. 496, tradução livre). Outro exemplo é o artigo , publicado em 1925, de Georges Michel, publicado em partes, intitulado "La doctrine sorélienne”. O autor analisa detidamente 
o pensamento de Sorel, destacando a sua crítica a Il Internacional e a sua "teoria dos mitos". (MICHEL, 1925, p.24).

Como sabemos, Mariátegui foi bastante influenciado por Sorel, e ente as diversas referencias que faz a ele, encontra-se o artigo intitulado "El hombre y el mito", em 1925, referindo-se diretamente ao autor como um dos mais altos representantes do pensamento francês do século XX (MARIÁTEGUI , 1994, p. 497-499), no qual apresenta sua visão acerca da importância do mito. No número 9, de maio de 1927, Amauta traduz um trecho de "Reflexiones sobre la violência", apresentado sob o título "Lenin y Sorel”, precedido da seguinte introdução:

Es poco conocida por los lectores hispano-americanos la famosa "Defensa de Lenin" por Jorge Sorel. No la hemos hallado aun en español en ninguna revista ni ninguno de los libros traducidos al castellano. Se trata, sin embargo, de un documento de extraordinaria importancia, que señala magistral y concretamente la conexión del gran teórico del sindicalismo revolucionario y la obra del genial jefe del comunismo ruso. En pueblos donde es frecuente que militantes y propagandistas que creen fielmente inspirarse fielmente en el sindicalismo manifiesten una total incomprensión de la revolución rusa la importancia de esas páginas de Sorel se duplica. La publicamos por esto traduciéndolas de la última edición francesa de las reflexiones sobre la violencia" (AMAUTA, 1927, p. 25)

Se não há dúvida de que Mariátegui tomou contato com Sorel no contexto italiano, inclusive pelas páginas de L'Ordine Nuovo, certamente a leitura em chave francesa se deu via Clarté.

Ao longo de seus quase dez anos de existência, Clarté atravessou inúmeras situações de crise financeira e de conflitos políticos, de diversas ordens, tanto internos como relacionados com o campo político e artístico de seu redor. Barbusse, apesar de manter-se como diretor por muitos anos, esteve no centro dos conflitos e acabou se afastando do grupo, e assumindo a direção de outra revista. As novas lideranças, então, em particular Pierre Naville, Victor Serge e Michel Fourrier, transformaram Clarté em uma revista crítica do stalinismo, em 1928: a revista La Lutte de Classes.

\section{A tarefa americana}

Como dito antes, a experiência de Clarté foi replicada em vários outros países, seja de forma indireta ou direta. Um exemplo paradigmático foi a revista Claridad do Peru, capitaneada por Haya de la Torre e da qual participou Mariátegui, interinamente, um pouco antes de sua ruptura com o líder da Aliança Popular Revolucionária Americana (APRA), em 1925. Na Argentina, Antônio Zamora cria o Editorial Claridad, em 1922, e em 1926 a revista de mesmo nome, de explícita relação com Clarté. Na Argentina, se pode notar a clara influência de Clarté em La Vida Literária e em Babel, coordenadas por Samuel Glusberg (de pseudônimo Enrique Espinoza), um dos principais interlocutores 
de Mariátegui naquele país e um dos principais divulgadores do seu trabalho, inclusive após sua morte (TARCUS, 2004).

Referências diretas e apropriações de elementos diversos de publicações "irmãs" foi um ponto comum no campo editorial do período. Experimentações em aspectos formais, estéticos, além do conteúdo propriamente dito, foram compartilhados por grupos e editores que expressam propostas ou ideologias similares, ainda que muitas vezes essa relação seja bastante tênue e retórica. Neste sentido, reportamos ao conceito de editorialismo programático de vanguarda:

El editorialismo programático fue el motor propulsor de estos diversos textos colectivos que aparecieran durante el vanguardismo y posteriormente, en las nuevas inflexiones que se abrieran com la década de los sesenta. En cuanto empresas editoriales lograran difundir, de manera inusitada, manifiestos, diarios, revistas, congresos, que contribuyeran a las ricas discusiones que constituyeran puntos de encuentro entre nuevos proyectos y nuevas prácticas de sujetos sociales nacientes (BEIGEL, 2003, p. 110, grifos meus).

Esta rede editorialista na América Latina conheceu um impressionante crescimento no início do século XX. Para se ter uma ideia, em 1918 havia no Peru 167 periódicos sendo publicados e, em 1929, esse número alcançava 475 títulos, conformando o que Fernanda Beigel chama de "explosão gutemberguiana" (BEIGEL, 2003a, p. 21). Ela marca a virada do século XIX para o XX e está intrinsecamente ligada à constituição de uma esfera pública, para a qual contribuíram os processos de alfabetização da população, em escalas mais amplas, e as inovações técnicas relacionadas à reprodutibilidade de obras de arte e de manuscritos. Tais conquistas da modernidade foram apropriadas por diferentes setores sociais, desde os meios populares, e também se expressaram no "pipocar" de revistas operárias de diferentes inspirações (TARCUS, 2004). Os leitores e, principalmente, os assinantes eram convocados permanentemente a contribuir com as tarefas de distribuição, de comercialização e divulgação, de forma militante. A maior parte dos empreendimentos editoriais envolveu-se com a edição de livros e obras, buscando impulsionar uma nova cultura e sociabilidade, a um só tempo moderna e socialista. A partir dessa perspectiva, de democratização do conhecimento, é que se deve inserir os propósitos de difusão cultural e educação através de periódicos. central nos empreendimentos aqui considerados, na qual se insere a permanente divulgação de livros, de revistas, de polêmicas e debates, tradução de obras e de textos políticos (como manifestos e discursos) e campanhas em prol da leitura, que se apoiavam nas possibilidades de acesso a baixo custo aos livros e revistas. Neste contexto, a Argentina gozava de destaque na época, pois o país conhecera um grande avanço em relação a alfabetização do povo. Revistas como Claridad argentina apostavam neste processo, acrescentando elementos situados a esquerda, a educação do povo e a popularização da cultura que crescia com a expansão do ensino e da alfabetização. A juventude peruana, por sua vez, expressa 
em sua própria Claridad esta proposição, através da construção de uma ampla Tribuna del Pensamiento Izquierdista. (MONTALDO, 1990; CASSONE, 1998)

Foi neste ambiente que o jovem Mariátegui iniciou sua carreira, inicialmente como entregador de jornais e linotipista, e, a seguir, como articulista, nos jornais El Tiempo, Mundo Limeño e na revista Lulu. Neste período, situado entre 1909 e 1919 - que sera chamado de "Idade da Pedra" - já se pode perceber vários elementos que, alguns anos depois, irão conformar uma obra consistente e original, tanto como escritor quanto como editor. Ajuda a criar o Jornal La Razón, na esteira das mobilizações estudantis decorrentes da Reforma de Cordoba, e logo a seguir, o periódico Nuestra Epoca. O enfrentamento com o Governo peruano, sob a presidência de Leguía, leva Mariátegui e outros companheiros a serem afastados do pais, em um período que ficou conhecido como "exílio" na Europa, entre outubro de 1919 e março de 1923, quando passa a residir na Itália, onde se especializará em assuntos internacionais, enviando seus artigos para diversos periódicos do Peru. Seu retorno ao Peru em 1923, demarcará uma nova etapa no seu trabalho, que ele definirá, anos depois, de tarefa americana:

\begin{abstract}
Yo no me sentí americano, sino en Europa. Por los caminos de Europa, encontré el país de América, que yo había dejado, y en el que había vivido casi extraño y ausente. Europa me reveló hasta qué punto pertenecía yo a un mundo primitivo y caótico; y al mismo tiempo me impuso, me esclareció el deber de una tarea americana... Europa me había restituido, cuando parecía haberme conquistado enteramente, al Perú y a América (MARIÁTEGUI, 1970, grifos meus)
\end{abstract}

Esta conhecida frase de Mariátegui demarca sua virada "anti-eurocêntrica", e foi repetida por ele, em diferentes ocasiões. Por isto, há várias referências diferentes, com relação a este trecho, todavia, a mais precisa, ao meu ver, seria a que foi escrita no artigo intitulado "Itinerário de Waldo Frank", publicada em Variedades: Lima, 4 de dezembro de 1929,e reunida, depois, no livro El alma matinal y otras estaciones del hombre de hoy, reeditado em 1970. Ela também remete à missão coletiva de consolidar no Peru e na América uma alternativa ao capitalismo cujas características era diferenciadas daquelas vivenciadas na Europa. Este projeto está, portanto, intrinsecamente relacionado com sua adesão ao marxismo e à luta socialista internacional, e, ao mesmo tempo, com a busca de compreensão de seu contexto - nacional e regional. Desde 1925, escreve regularmente para uma seção que intitulou "Peruanicemos el Peru", no qual as principais reflexões que aparecem, a seguir, nos Sete ensaios, estão presentes. Deste projeto faria parte a consolidação de uma rede editorial programática, em todo o continente, e, no seu caso, a consolidação de uma editora própria. Porém, sem nunca abandonar o trabalho como articulista, colaborando com outros periódicos quando de seu retorno à terra natal, é como editor que Mariátegui consolida seu mais importante papel, no sentido de um intelectual orgânico preocupado com a organização da cultura ligada à classe proletária, como sugere Leila Escorsim (2006). 
O conhecimento do métier editorial vinha do período anterior a viagem à Europa, mas consideramos que o principal marco na trajetória editorial de Mariátegui é posterior a seu retorno ao Peru. O primeiro momento seria aquele situado entre 1923 e 1925, no qual ele assume interinamente a direção da revista Claridad, e o segundo momento, entre 1925 e 1930, quando são criadas a Sociedad Editorial Amauta e a Librería e Imprenta Minerva, e se publicam a revista Amauta e o jornal Labor.

Claridad foi criada por Haya de la Torre, principal liderança do movimento estudantil peruano que se firmou no cenário político a partir da Reforma Universitária de Córdoba. Reunida na Federação dos Estudantes Peruanos. Essa nova geração de estudantes organizou, em 1923, as Universidades Populares Gonzáles Prada, destinadas à formação das classes populares em várias cidades do Peru, e elas são referidas permanentemente nas páginas de Claridad. Tão logo retorna a seu país, vindo da Europa, Mariátegui é convidado a proferir algumas aulas na Universidade Popular Gonzáles Prada de Lima e, a partir de então, se aproxima de Haya de La Torre. A aliança entre os dois se consolida por meio da colaboração de Mariátegui com Claridad, revista que inicialmente se apresenta como porta-voz da Federação dos Estudantes Peruanos. Mariátegui escreve, no primeiro número de Claridad, de $1^{\circ}$ de maio de 1923 , o artigo intitulado "El ocaso de la civilización europea". A consigna do periódico "Todos los espíritus libres del Peru son considerados miembros colaboradores de Claridad" explicita o alinhamento com o Grupo Clarté. No primeiro número encontra-se uma caricatura de Barbusse com a legenda "El fundador de la Internacional del Pensamiento". E, ainda, a primeira parte de seu livro Con el cuchillo entre los dientes, com tradução do francês (Le couteau entre les dents), que seguiria sendo publicado entre os números 2 e 6. Com 20 páginas, esse número tem também muitas ilustrações e artigos de diversos autores peruanos.

Observa-se, na capa acima, as semelhanças com Clarté nos logotipos usados. A partir do número 5, de março de 1924, como se pode ver acima, Mariátegui assume como diretor interino e logo depois como seu editor principal, em razão do exílio de Haya de la Torre no México. Já nesse momento, muda-se a referência da revista para "Órgano de la Federación Obrera local de Lima y de la Juventud Libre del Peru", o que sinaliza mudanças mais substanciais que se expressarão no próprio conteúdo. Estas diferenças já expressam os germens do afastamento que levará, alguns anos depois, em 1927, a ruptura entre Mariátegui e Haya de la Torre:

A partir del número 5 hay un evidente giro doctrinario: abandonase el tono estudiantil (...). El número está dedicado a Lenin, quien murió el 21 de enero. En ella se incluye el editorial de homenaje - escrito por Mariátegui en base de su conferencia en la Universidad Popular -, un artículo de Trotsky, las tesis de Lenin sobre la dictadura del proletariado y el testimonio de Charles Gide sobre la Rusia Soviética" (PORTOCARRERO, 1994, p. 15).

Durante sua atuação como diretor interino, Mariátegui se dedica também a organizar a Editorial Obrera Claridad, cujo objetivo seria contribuir com a organização da classe operária. No número 5 , Claridad chega a publicar a proposta do estatuto 


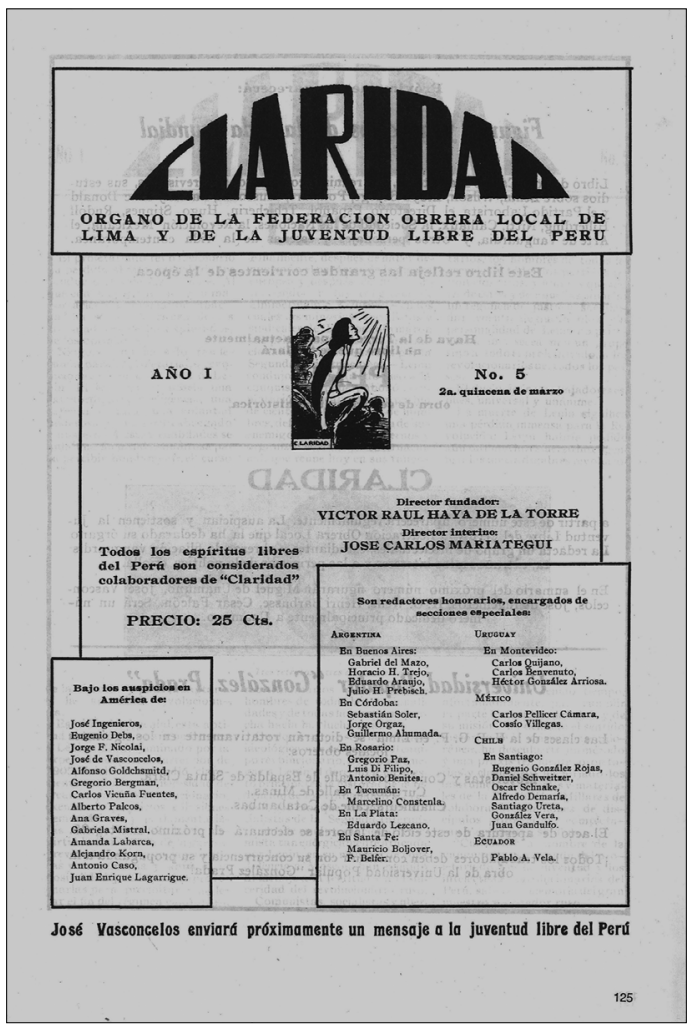

Fig. 04. Capa da Revista Claridad, n. 5, Março de 1924

dessa editora, que teria como foco principal a publicação de um jornal operário diário e uma gestão cooperativada (PORTOCARRERO, 1994, p. 16). À luz da experiência de Clarté, a proposta seria organizar o trabalho editorial de forma completa, ou seja, o mesmo grupo tocaria a gráfica, a editora e a livraria. Mariátegui retomará o mesmo projeto logo a seguir, já distante de Claridad e de Haya de la Torre, com a proposta de criação de uma revista e de uma editora própria.

Mas, nas publicações feitas no âmbito de Minerva e, depois, da Sociedad Editora Amauta, as referências a Clarté serão menos diretas do que em Claridad. Elas podem ser percebidas mais pelo temário abordado, por aspectos editoriais propriamente ditos, e menos por referências diretas que sugerissem uma "filiação". Sabemos que Mariátegui seguiu como assinante e leitor assíduo da revista até o final de sua vida. Nas correspondências compiladas por seus familiares, constam duas destas, confirmando sua relação com o grupo. Ambas contêm assinaturas indecifráveis, em nome do comitê editorial. Uma delas, datada de 22 de setembro de 1926, com os seguintes dizeres, originalmente em francês: 
Querido Camarada, como anunciamos en el último número de Clarté, suspendimos el servicio del libro del mes. Revisando las cuentas, averiguamos que la suya sigue siendo deudora de la suma de 41,05. Para poder clausurar nuestra contabilidad, le agradeceríamos tenga a bien hacernos llegar el saldo lo más pronto posible. Esperando, reciba, camarada, nuestros saludos fraternales (MARIÁTEGUI, 1994b, p. 1796).

A outra data de 4 de abril de 1927, e refere-se ao recebimento de Revista Amauta, bem como ao trabalho de Mariátegui no trabalho de difusão da revista francesa:

Querido camarada: He recebido su carta del 4 de marzo. Nosostros recibimos en efecto su revista y se lo agradecemos. Pido disculpas por no haberles enviado más pronto Clarté pero desde ahora les haremos el servicio desde luego estamos a su disposición para todo envio suplementário de Clarté que Uds. deseen para la difusión. Saludos fraternales (MARIÁTEGUI, 1994b, p. 1848).

Assim, as referências diretas à Clarté, que expressam o desejo de uma "filiação" com o grupo, como ocorrera em Claridad, desaparecem no segundo momento. Elas não desaparecem, de todo, porém: podem ser percebidas de formas mais sutis, seja pela temática, pelos autores e pelos aspectos editoriais propriamente ditos.

A Sociedad Editora Amauta, sucessora da Liberaria Minerva, criada em 1925, responsabilizou-se pelos periódicos Amauta, entre 1926 e 1930, e Labor, entre 1928 e 1929. A empresa contou com o apoio decisivo de Júlio César, irmão de Mariátegui, que dispunha de recursos econômicos para importar a máquina tipográfica da Itália e foi gerente administrativo e sócio majoritário da empresa. Mariátegui era editorgeral, junto com Felix del Valle, e sócio minoritário que desenvolveu outros trabalhos no ramo editorial como, por exemplo, a impressão de livros escolares e correlatos. Este trabalho contribuía com a atividade principal, que era a edição das publicações próprias, e as vezes se sobrepunham a estas, como se pode ver nas diversas cartas trocadas entre Mariátegui e Samuel Blusberg,entre outros editores, a respeito das dificuldades financeiras e atrasos nas diversas edições de periódicos e livros (MARIÁTEGUI, 1994b, p. 1869-2086).

O jornal Labor destinava-se à classe operária, em ascensão naquele momento: em 1928 foi criado o Partido Socialista do Peru e, alguns meses depois, a CGTP (Confederación de los Trabajadores del Peru), ambos tendo à frente Mariátegui. Labor era visto como uma extensão de Amauta, tendo reverberado muitas das discussões feitas nessa última. Tinha uma média de oito páginas, com impressão em preto e branco, e o preço era bastante acessível. Labor apresenta-se como um "quincenario de información y ideas publicado por la Sociedad Editorial 'Amauta'”, articulado com a tarefa de difusão cultural, com o propósito de "llegar a los sectores del público a los cuales Amauta no alcanza” e ter "el mismo espíritu y programa” (LABOR, 1970, p. 6). 


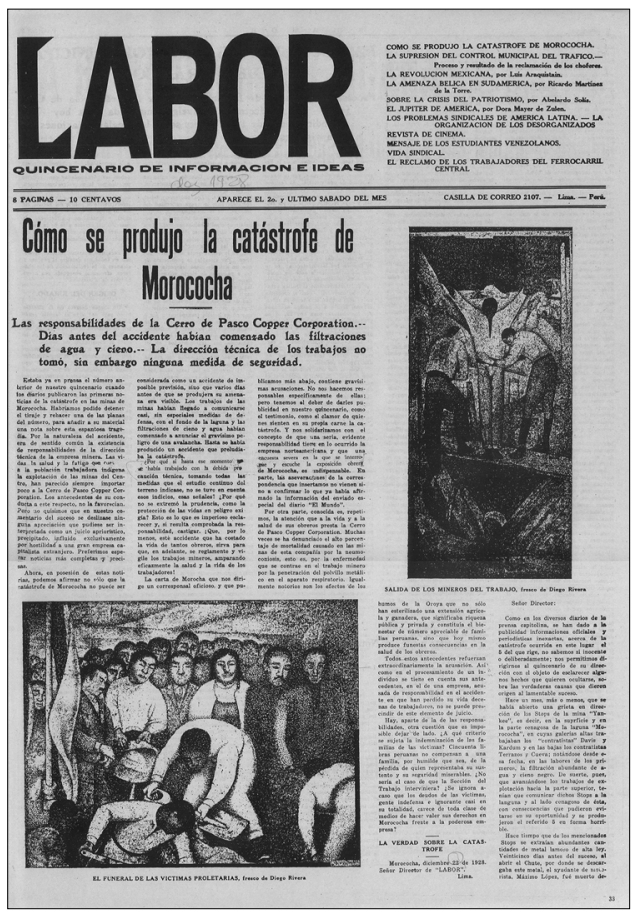

Fig. 05. Jornal Labor, n. 4, Dezembro de 1928

Observa-se neste número a presença de uma obra de Diego Rivera, a luz da preocupação de Labor em veicular as obras de arte das vanguardas da época, fazendoas chegar a um amplo conjunto de trabalhadores. A matéria com a qual se vincula a obra trata de um dos "acidentes" mais frequentes que atingia os trabalhadores das minas na Bolivia e no Peru, naquele momento, e a forma como eram tratados. E, neste sentido, assinalando uma das principais diferenças das vanguardas socialistas com outras revistas vanguardistas desta época que se restringiam a atingir um publico mais elitizado e não a classe trabalhadora.

A revista Amauta recebeu originalmente o nome de Vanguardia. Ela chegou a ser anunciada em outros periódicos como "Revista semanal de renovación ideológica Voz de nuevos tiempos", quando Mariátegui ainda dirigia Claridad. Porém, antes de sua publicação definitiva, ocorre a mudança de nome. Amauta será a espinha dorsal do projeto mariateguiano. A mudança de nome, ocorrida alguns dias antes da primeira edição, em 1926, reflete a importância que a questão indígena assume na reflexão de Mariátegui e seus interlocutores, numa conjuntura em que os movimentos indígenas e o indigenismo, em suas diferentes expressões, se impunham no Peru (ALIMONDA, 1994). O nome correspondia à noção de líder, em quéchua, e foi proposto pelo artista plástico José Sabogal, que ocupará um papel de destaque na revista. 
O indigenismo no Peru do século $X X$ se expressou em duas correntes: uma tendência estética cultural e outra, política, favorável à libertação do indígena, junto a agitações populares mais amplas, em vários centros urbanos do país. Não se tratava de um movimento indígena autóctone, mas, antes, da busca de construção de uma identidade nacional na qual adquirem positividade justamente os setores menosprezados pelas elites coloniais e a burguesia imperialista: operários, campesinos, indígenas, cholos ou mestiços (BEIGEL, 2006, p. 207). Neste sentido, a aliança entre Mariátegui e Sabogal, expressa na revista Amauta, pode ser entendida.

Com uma média de 45 páginas e $24 \mathrm{~cm} \times 33 \mathrm{~cm}$ de tamanho, Amauta foi editada mensalmente e vendida a preços módicos, tanto os números avulsos como as assinaturas anuais. Chegou a ter 100 páginas em seus últimos anos, quando o formato diminuiu para $24 \mathrm{~cm} \times 16 \mathrm{~cm}$. Como Clarté, a revista publicava com frequência matérias e informes sobre a sua sustentação econômica, pretendendo funcionar como um empreendimento cooperativo e anticapitalista, através do apoio de acionistas ("amigos de Amauta") e do ativismo ou da militância de seus assinantes e leitores. Por este motivo, Amauta e Labor não chegou apenas a outros países, mas capilarizou-se pelo vasto interior do Peru e de outros países andinos. Mariátegui foi incansável neste sentido, projeto para o qual contou com apoio de seus interlocutores e camaradas ligados aos movimentos sociais que vivam nas cidades e pueblos mais isolados e pobres (BEIGEL, 2006). O contexto de mobilização de operários, estudantes e indigenas impulsionou este processo. A capacidade de interlocução e o capital social adquirido ao longo dos anos o consolidou.

Além do editorial e de artigos de fundo de seus articulistas, a revista mantinha uma seção dedicada a publicar documentos e manifestos e outra reservada a resenhas e anúncios de livros, revistas, discos e filmes. Este era um espaço privilegiado de diálogo entre revistas e editoras, mas o conjunto dos artigos e ilustrações também expressava um intenso intercâmbio de articulistas e artistas.

Contava com a importante contribuição de tradutores, como também encontramos em Clarté. Os exemplares eram enviados a outras editoras e escritores, com o intuito de receber apreciação. Clarté recebeu exemplares de Amauta, dos Sete ensaios e outros livros. Os editores da nova geração de Clarté, em particular Pierre Naville, trataram com um certo desprezo estes materiais, como analisamos em outro artigo sobre o tema (TORNQUIST, 2017). Essa posição contrasta com a apreciação positiva que Ihe reservara Barbusse, anos antes. Em carta enviada à Mariátegui, datada de maio de 1926, o escritor francês assim se manifesta:

Recebi vossa obra La escena contemporánea. Como estou desolado de conhecer mal a linda língua espanhola - que é de todas as línguas vivas que conheço a que eu admiro mais - e que me impede de ler fluidamente sua obra. Mais do que nunca nos ocupamos de agrupar as forças intelectuais internacionais. (...) Eu me colocarei sem dúvida em breve com você para isto, porque penso que você representa em seu país os elementos mais ardentes e lúcidos que necessitamos chegar a organizar em bloco (MARIÁTEGUI, 1994b, p. 1.786). 
Apesar da importância dos artigos internacionais, Amauta sera carregada de "peruanidade" e latinoamericanidade. Na capa do número 16 (figura 06), há um artigo sobre Barbusse, mas a maioria das matérias refere-se a América e e escrita por autores latino-americanos.

Amauta dedicou grande parte de suas páginas à arte e à cultura: cerca de $41 \%$ do número total de referências em artigos (BRUCKMAN, 2012, p. 65), a maioria deles tratando de artistas latino-americanos e, entre os peruanos, os que faziam parte do chamado indigenismo pictórico. As capas são exemplares no sentido de dar vazão a produção desta escola, e são editadas com cores, como se pode ver na figura 07. Já as reproduções que compõe a parte interna da revista, são acompanhadas de matérias específicas, de varias páginas, geralmente com destaques, eventualmente, em cores pastéis e papel diferenciado, acompanhadas de comentários de curadores ou críticos.

Por exemplo, no número 14, de abril de 1928, a matéria "Arte mexicana" é dedicada a jovens pintores daquele país, e a seguir, no número 15, a arte peruana aparece com obras de Carmen Saco e Ricardo Flores. No número 16 uma matéria traz obras de José Sabogal expostas em Buenos Aires. Esses artistas compuseram um importante

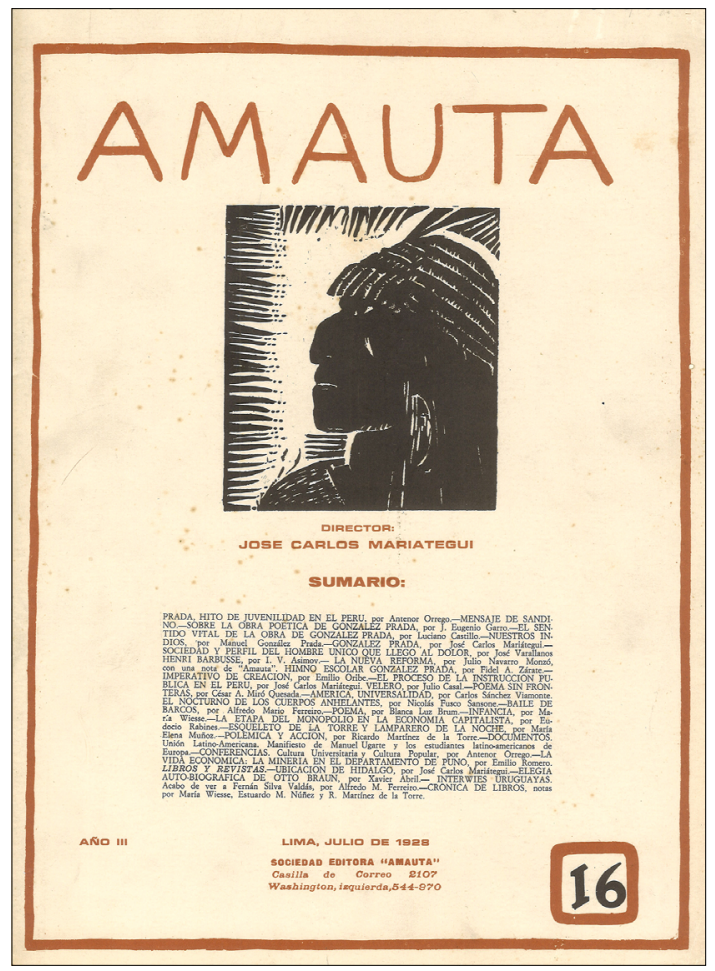

Fig. 06. Capa de Amauta, n. 16, Julho de 1928. 


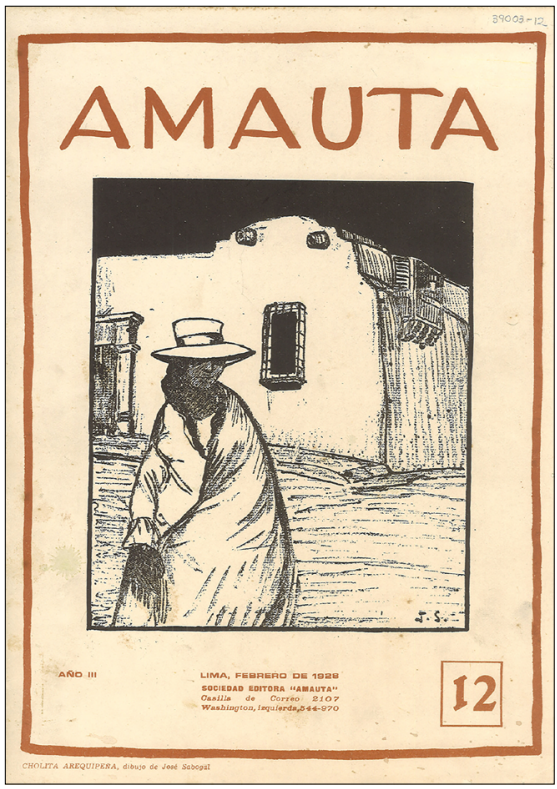

Fig. 07. Capa de Amauta, n. 12, Fevereiro de 1928.

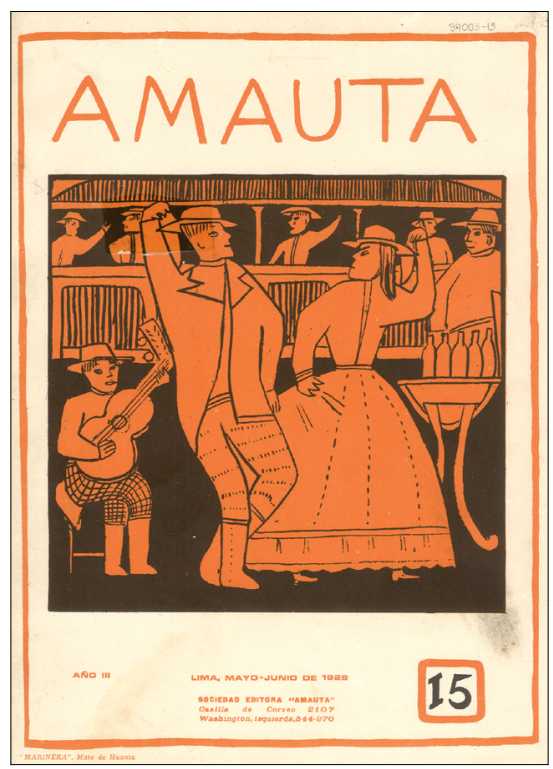

Fig. 08. Capa de Amauta, n. 15, Junho de 1928. 
movimento estético, influenciado pelas vanguardas "europeias", mas em busca de uma identidade nacional indígena e/ou mestiça, como em outros países da América Latina. O indigenismo estético, também chamado de pictórico ou, ainda, "indigenismo-2", expressou a busca de uma articulação entre elementos universais e nacionais, com uma clara adesão aos elementos populares, de onde emerge a aliança com o socialismo mariateguiano.

\section{À guisa de conclusão}

A amplitude dos temas abarcados em Amauta - do indigenismo à Revolução Soviética, da psicanálise à política internacional - expressa, a meu ver, o mesmo desejo de compreender o mundo contemporâneo que Clarté manifestava desde seu início. Mas não se pode ver na revista uma mera reprodução das temáticas e das "pautas" europeias: ao contrário, Amauta foi original justamente por ter tratado de uma grande diversidade de temas e de abordagens a respeito da situação peruana.

A adesão de Mariátegui a Clarté se expressa no seu compromisso com a difusão da cultura e do conhecimento universais. A criação das suas próprias revistas e o vínculo permanente com Clarté são evidentes na sua trajetória. Mas se ela se faz presente no seu projeto editorial, isto não ocorre de forma direta.

Mariátegui apropriou-se do que Ihe interessava da experiência francesa para construir um projeto editorial e político condizente com os dilemas de sua realidade americana. Aproveitou o exemplo do grupo francês no sentido de criar uma ampla rede de apoiadores, através de uma política de subscrições e de assinaturas bastante ampla, na perspectiva de uma educação e formação revolucionária, em todos os sentidos da existência. Claridad, Amauta e Labor são periódicos firmemente ancorados na realidade latino-americana e articulados, ao mesmo tempo, com o contexto mundial.

Assim, a obra de Mariátegui foi construída no âmbito de sua atividade como organizador da cultura com vistas à construção de um projeto de transformação radical no Peru. Avesso - embora não alheio - ao mundo acadêmico, autodidata e intelectual forjado na interlocução com os sujeitos políticos de seu tempo, construiu o melhor de suas reflexões em suas palestras, em seus artigos e nos periódicos que viabilizou. 0 seu empenho na consolidação de uma ampla rede editorial programática de vanguarda esteve imbuído da inspiração clartéiste - de promover uma "revolução dos espíritos". Nesse sentido, compreendem-se as ações repressivas do governo Leguía sobre a editora, em especial em 1927 (com a suspensão da publicação de Amauta por vários meses e a detenção de Mariátegui por alguns dias) e em 1928 (com a apreensão de Labor), expressando a importância que essas publicações tiveram no acirramento dos conflitos de classes no Peru naquele período (QUIJANO, 2008, p. 238-237).

A publicação de livros e periódicos a baixo custo e o empenho na sua ampla difusão esteve relacionada ao propósito de socialização da cultura, facilitando o acesso de amplas massas às reflexões teóricas sobre a realidade social, local e mundial, na qual estavam inseridas. A publicação de obras originais - muitas delas hoje conhecidas como livros - em partes, em periódicos populares, era bastante comum nos meios socialistas 
desde o século XIX. Tratava-se de garantir o acesso a informações fidedignas, bem como à formação e educação do proletariado, na trilha aberta no século XIX, pelos anarquistas e socialistas, a partir da proposta de educação socialista e revolucionaria do proletariado. Esta se expressou, de forma paradigmática, no empenho de Marx, por exemplo, em adaptar o primeiro volume de $O$ capital para que fosse difundido amplamente aos trabalhadores, tornando-a uma obra popular (TARCUS, 2018). Clarté seguiu esta tradição desde os seus primeiros números, e não foi diferente com os periódicos coordenados por Mariátegui esteve vinculado. E, considerando a realidade latino-americana, o esforço deste Itimo se reveste da importância certamente maior.

Amauta - a editora, a revista e o próprio Mariátegui, que passou ainda em vida a ser chamado de El Amauta - guarda sua riqueza e atualidade justamente por articular, como de forma original, elementos locais e universais, sem cair no eurocentrismo nem resvalar para o excepcionalismo, duas "tentações" opostas que estiveram presentes, entre outras perspectivas, no pensamento marxista latino-americano, como coloca Löwy (1999, p. 20). A relação de Mariátegui com o movimento comunista europeu, viabilizada por movimentos como Clarté, contribuiu para que pudesse levar a cabo, no restrito tempo de sua vida biológica, a elaboração desta tarefa americana.

\section{Referências}

ALIMONDA, Hector. Mariátegui: vanguardas, tradição e modernidade. Estudos Sociedade e Agricultura, Rio de Janeiro, n. 3, p. 101-113, 1994.

AMAUTA. Edición facsimil. Lima: Editora Amauta, 1994.

BEIGEL, Fernanda. El itinerário y la brújula. Buenos Aires: Editorial Biblos, 2003a.

. Las revistas culturales como documentos de la historia latinoamericana. Utopia y Praxis, ano 8, n. 20, p. 105-115, marzo 2003b.

. Una mirada sobre otra: el Gramsci que conoció Mariátegui. Estudos de Sociologia, Araraquara, v. 10, n. 18/19, p. 23-49, 2005.

La epopeya de una generación y una revista: las redes editorialistas de Mariátegui en América Latina. Buenos Aires: Biblios, 2006.

BERTH, Edouard. Georges Sorel. Clarté, n. 21, p. 495-496, 1922.

BRUKCMAN, Mónica. José Carlos Mariátegui, la revista Amauta y el pensamiento marxista latino-americano. Comunicação e Política, n. 30, v. 3, p. 54-74, set.-dez. 2012.

CASSONE, Florencia Ferreira. Claridad y la organización de la izquierda latinoamericana. Anuário de Filosofia Argentina y Americana, n. 15, 1998. 
CRESPO, Regina. Revistas culturais e literárias latino-americanas: objetos de pesquisa, fontes de conhecimento histórico e cultural. FRANCO, Stella Maris; JUNQUEIRA, Mary Anne (Org.). Cadernos de Seminários de Pesquisa. São Paulo: USP/Humanitas, 2011, p. 98-116.

CUENOT, Alain. Clarté 1919-1924: du pacifisme à l'internacionalisme prolétarien. Tome I. Paris: L'Harmattan, 2003 a.

CUENOT, Alain. Clarté 1925-1928: du surréalisme au trotskisme. Tome II. Paris: L'Harmattan, 2003b.

ESCORSIM, Leila. Mariátegui: vida e obra. São Paulo: Expressão Popular, 2006.

HALL, Michael; PINHEIRO, Paulo Sérgio. O grupo Clarté no Brasil: da revolução nos espíritos ao Ministério do Trabalho. In: PRADO, Antonio Arnoni (Org.). Libertários no Brasil: memória, lutas, cultura. São Paulo: Brasiliense, 1986, p. 251-287.

LABOR. Edición facsimil. Lima: Editora Amauta, 1994.

LÖWY, Michael. O marxismo na América Latina. São Paulo: Editora Perseu Abramo, 1999.

LÖWY, Michael. José Carlos Mariátegui e o Surrealismo. Lutas Sociais, v. 17, n.30 jan-jun. de 2013, p. 17-36.

LIGUORI, Guido. Georges Sorel. Dicionário Gramsciano. São Paulo: Boitempo, 2017. p. 740-743. (Verbete).

MARIÁTEGUI, José Carlos. La lucha final. Mundial, marzo 1925. In: Mariátegui Total. Lima: Empresa Editora Amauta, 1994a.

MARIÁTEGUI, José Carlos. Polémica Finita. Amauta, n. 7, março de 1927.

MARIÁTEGUI, José Carlos. Mariátegui Total. Lima: Empresa Editora Amauta, 1994b.

MARIÁTEGUI, José Carlos. Siete ensayos sobre la realidad peruana. Caracas: Biblioteca Ayacucho, 2007.

MARIÁTEGUI, José Carlos. El alma matinal y otras estaciones del hombre de hoy". [on line]. [Data de consulta: 11 de abril de 2019]. Disponivel em: https://www. marxists.org/espanol/mariateg/oc/el_alma_matinal. Acesso em 12.4.2019.

MICHEL, Georges. La Doctrine Sorélienne. Clarté n. 71, p. 24-28, 1925.

MONTALDO, Graciela. Los pensadores y Claridad: una propuesta cultural de la izquierda argentina (1922-1941). Cahiers du CRICCAL, Paris, n. 4/5, p. 421-430, 1990.

NAVILLE, Pierre. Notre travail revolutionnaire - L'enquête de Clarté. Clarté n.5, p. 190-192, 1927. 
NETTER, Marie Laurence. Les correspondances dans la vie intelectuelle introduction. Mille Neuf Cent, Paris, n. 8, p. 5-9, 1990.

PARIS, Robert. La formation idéologique de José Carlos Mariátegui. Presenté pour le Titre de Docteur de $3^{\mathrm{e}}$ cycle. Paris, École Pratique des Hautes Études (VI section), 1969.

PORTOCARRERO, Ricardo. Introducción à Claridad. In: Claridad - Edición Fac Símile, Empresa Editora Amauta, Lima, 1994, p. 7-18.

QUIJANO, Anibal. Prologo. In: MARIÁTEGUI, José Carlos. Siete ensayos sobre la realidad peruana. Caracas: Biblioteca Ayacucho, 2007. p. I-CXXIX.

RACINE, Nicole. Une revue d'intellectuels communistes dans les années vingt: Clarté (1921-1928). Revue Française de Sciences Politiques, $17^{\circledR}$ année, p. 468-483, 1967.

SILVA, Michel Goulart. Socialismo e revolução nas páginas de Clarté. Tempos Históricos, v. 21, p. 52-73, $2^{\circ}$ sem. 2017.

TARCUS, Horacio. Revistas, intelectuales y formaciones culturales izquierdistas en la Argentina de los 20. Revista Iberoamericana, n. 208-209, p. 749-772, 2004.

TARCUS, Horacio. La biblia del proletariado. Buenos Aires: Siglo Veintiuno, 2018.

TORNQUIST, Carmen Susana. Las relaciones entre Clarté y Amauta: anotaciones de pesquisa. Utopía y Praxis Latinoamericana. Abril-junio 2017, vol. 22, n. 77, p. 101-112. [on line]. Disponível em: <http://roduccioncientificaluz.org/index.php/utopia/ article/view/22539>. Acesso em: 1 de março de 2018.

\section{Notas}

1 Tomamos como referência, para fins deste artigo, a cronologia publicada na edição da Biblioteca Ayacucho de "Siete Ensayos de Interpretacion de la Realidad Peruana”, e prefaciada por Anibal Quijano.

2 Editorial e Librería Minerva foram criadas em 1925, sendo sucedidas pela Sociedad Editoral Amauta, em 1927. Houve algumas diferenças em relação à organização das duas empresas, porém ambas correspondem ao mesmo projeto editorial protagonizado por Mariátegui.

3 Consultados no acervo de microfilmes da Bibliothèque Sainte-Géneviève e da Bibliothèque Nationale, em Paris, entre 2015 e 2016.

4 Consideraram-se também os documentos microfilmados referentes às revistas argentinas consultados no acervo do CeDinCl, em Buenos Aires, em 2018.

5 Uso o termo "revista" de forma genérica, mas atentando para o fato de que os primeiros números de Clarté foram boletins. 
6 Lefebvre foi um dos principais responsáveis pela "sovietização" de Clarté, tendo falecido em circunstâncias obscuras no retorno de um congresso sindical em Moscou, em 1920. Clarté permanecerá até o final de seus dias fazendo referências a ele, em datas comemorativas e em artigos.

7 “Vous ne savez pas qui est Mariátegui? Et bien... c'est une nouvelle lumière de’Amérique; un spécimen nouveau de l'hombre américain."

80 feminismo foi um tema abordado em diversos momentos, em Clarté, e correspondeu ao crescimento das organizações de mulheres socialistas naquele contexto. Mas, face a complexidade do tema, não analisaremos em detalhe esta questão, aqui.

9 Barbusse permanece no Partido Comunista Francês e, portanto, alinhado à III Internacional e à União Soviética até 1935, quando falece, em Moscou - não sem antes ter escrito uma biografia de Stálin.

Carmen Susana TORNQUIST é Licenciada em História, Mestre em Sociologia Política pela Universidade Federal de Santa Catarina (1992) e Doutora em Antropologia Social pela Universidade Federal de Santa Catarina (2004). É professora titular da Universidade do Estado de Santa Catarina, onde atua no departamento de Geografia e no Programa de Pós Graduação em Planejamento territorial e desenvolvimento sócio-ambiental, colaboradora - INTC Instituto Brasil Plural. Realizou Estágio Pós Doutoral na EHESS (CEIFR) sob a supervisão de Michael Löwy.

Recebido em: 05/12/2018 